\title{
UTILIZAÇÃO DE APLICATIVOS GRATUITOS PARA ATIVIDADE DE CAMPO NO ENSINO' DE TRIGONOMETRIA NO TRIÂNGULO RETÂNGULO
}

\author{
Thiago Beirigo Lopes² \\ Edna Lopes Hardoim ${ }^{3}$
}

\section{RESUMO}

As atividades de campo têm figurado como uma excelente estratégia para o ensino das ciências naturais. Ao imaginar que as atividades de campo também podem contribuir com o ensino de matemática, surge a questão de pesquisa: "A atividade de campo pode ser utilizada para prover ambientes propícios ao ensino de matemática?". Diante disso, neste artigo é apresentada uma atividade de campo no ensino de matemática com o subsídio das Tecnologias de Informação e Comunicação (TIC) como instrumentos utilizados durante seu desenvolvimento. Tendo como objetivo o de verificar se a atividade de campo pode auxiliar no ensino de razões trigonométricas no triângulo retângulo ao se fazer medidas de alturas de difícil acesso. Para atingir tal objetivo, essa investigação ocorreu com uma turma do $2^{\circ}$ ano do ensino médio-técnico do Instituto Federal de Mato Grosso, Campus Confresa. Os parâmetros das atividades foram elaborados conjuntamente com os estudantes, que se dividiram em 3 grupos, realizando as atividades de modo extraclasse e tendo orientações por meio das TIC. Esse estudo mostrou que as atividades de campo podem favorecer 0 ensino de matemática que habitualmente é realizado dentro da sala de aula, pois os estudantes sentiram-se integrantes do processo e motivados por terem transpassado o ambiente da própria sala de aula.

Palavras-chave: Atividades de Campo. Tecnologias de Informação e Comunicação. Ensino de Matemática. Trigonometria.

\footnotetext{
1 Em todo o texto foi evitado utilizar o termo dicotômico ensino-aprendizagem ou alguma de suas variações, pois acredita-se que não há ensino sem aprendizagem, ou seja, não se cabe desassociar a aprendizagem como resultada do ensino. Acredita-se também que se não houve aprendizagem, então consequentemente não houve ensino. Já a recíproca não é válida, pois pode haver aprendizado sem haver tido o ensino.

2 Doutorando em Educação em Ciência e Matemática. Programa de Pós-Graduação em Educação em Ciências e Matemática (PPGECEM) da Universidade Federal de Mato Grosso (UFMT). E-mail: thiagobeirigolopes@yahoo.com.br

3 Doutora em Ecologia e Recursos Naturais (UFSCar). Professora do Programa de PósGraduação em Educação em Ciências e Matemática (PPGECEM) da Universidade Federal de Mato Grosso (UFMT). E-mail: ehardoim@terra.com.br
} 


\title{
USE OF FREE APPLICATIONS FOR FIELD ACTIVITY IN TEACHING TRIGONOMETRY ON TRIANGLE RECTANGLE
}

\begin{abstract}
Field activities have figured as an excellent strategy for the teaching of the natural sciences. By imagining that field activities can also contribute to mathematics teaching, the research question arises: "Can field activity be used to provide environments conducive to teaching mathematics?" In this article, it is presented a field activity in the teaching of mathematics with the subsidy of Information and Communication Technologies (ICT) as instruments used during its development. The activity aimed to verify if the field activity can help in the teaching of trigonometric ratios in the triangle rectangle when making measures of heights of difficult access. To achieve this objective, the investigation involved a class of sophomore students attending technical high school at the Federal Institute of Mato Grosso, Campus Confresa. The parameters of the activities were produced together with the students, who were divided into three groups, conducting the activities out of classroom time and being advised through ICT. This study showed that field activities can favor the teaching of mathematics that is usually done in the classroom because the students felt part of the process and motivated by taking learning beyond the classroom.
\end{abstract}

Keywords: Field Activities. Information and Communication Technologies. Mathematics Teaching. Trigonometry.

\section{LA UTILIZACIÓN DE APLICACIONES GRATUITAS PARA LA ACTIVIDAD DE CAMPO EN LA ENSEÑANZA DE TRIGONOMETRÍA EN EL TRIÁNGULO RETÁNGULO}

\section{RESUMEN}

Las actividades de campo han figurado como una excelente estrategia para la enseñanza de las ciencias naturales. Al imaginar que las actividades de campo también pueden contribuir con la enseñanza de matemáticas, surge la cuestión de la investigación: "¿́la actividad de campo puede ser utilizada para proveer ambientes propicios a la enseñanza de matemáticas?". En este artículo se presenta una actividad de campo en la enseñanza de matemáticas con el subsidio de las Tecnologías de Información y Comunicación (TIC) como instrumentos utilizados durante su desarrollo. El objetivo es verificar si la actividad de campo puede auxiliar en la enseñanza de razones trigonométricas en el triángulo rectángulo al hacer medidas de alturas de difícil acceso. Para alcanzar ese objetivo, esta investigación ocurrió con una clase del $2^{\circ}$ año de la enseñanza media-técnica del Instituto Federal de Mato Grosso, Campus Confresa. Los parámetros de las actividades fueron elaborados conjuntamente con los estudiantes, que decidieron dividirse en 3 grupos, realizando las actividades de modo extra-clase y teniendo orientaciones por medio de las TIC. Este estudio mostró que las actividades de campo pueden favorecer la enseñanza de matemáticas que habitualmente se realiza dentro del aula, pues los estudiantes se sintieron parte del proceso y motivados por haber traspasado el ambiente de la propia sala de clase.

Palabras clave: Actividades de campo. Tecnologías de Información y Comunicación. Enseñanza de Matemáticas. Trigonometría. 


\section{INTRODUÇÃO}

Um dos maiores desafios do professor em sua prática nos tempos atuais é o de elaborar atividades que possam ter um bom desenvolvimento durante as aulas de modo que propiciem uma aprendizagem que contribua para que os estudantes se tornem capazes de exercer sua plena cidadania.

Nesse contexto, as atividades de campo têm figurado como uma excelente estratégia para o ensino das ciências naturais, principalmente no ensino de biologia. Colocar os estudantes em contato direto com o objeto de estudo, extrapolando as paredes de uma sala de aula ou as páginas de um livro didático, pode ser um recurso que propicie o estímulo necessário para que aflore o interesse nos estudos escolares.

Ao imaginar que as atividades de campo também podem contribuir com o ensino de matemática, surge a questão de pesquisa: "A atividade de campo pode ser utilizada para prover ambientes propícios ao ensino de matemática?". Pois, como uma prévia de resposta a esta questão, o desenvolvimento da matemática tem historicamente se fundamentado na necessidade humana para entender $o$ mundo e em suas relações interpessoais. Criando novos mecanismos, ferramentas e métodos para conseguir mensurar, modelar e solucionar tais situações.

No que tange ao ensino de matemática, é necessário acentuar a curiosidade do estudante de maneira que se "estabeleçam relações cognitivas entre o conteúdo que é ensinado e como o conhecimento sobre esse conteúdo é estabelecido intelectualmente" (LOPES, COSTA; OLIVEIRA, 2016 , p. 2). Não podendo se pautar em uma metodologia onde somente se procura a resposta ou solução que o professor deseja e exige, modelo esse enfaticamente criticado por Kamii (2012). Tendo, então, de explorar sua utilidade em aplicações presentes ou futuras no cotidiano.

Segundo Kenski (2003), é notável a crescente necessidade de utilização das Tecnologias e Informação e Comunicação (TIC) na prática professor. Pois em nossa atualidade, apesar da quantidade e variedade de eletrônicos, redes sociais e outros que inundam os estudantes de 
informações e sensações, de modo geral, as instituições de ensino se mantiveram estancadas quanto à sua renovação e reinvenção diante dessa sempre renovada realidade. Além de se manter desse modo, tem-se como fator agravante de resistência em relação à utilização dessas tecnologias nos métodos de ensino. Tendo casos de leis federais, estaduais e municipais que proibiram, e ainda proíbem, os estudantes de adentrarem nos ambientes escolares em posse de aparelhos eletrônicos pessoais.

Com tais situações, é reforçada a impressão de que a escola prefere cercear-se em relação às inovações tecnológicas do que incorporar essas tecnologias em suas práticas de ensino. Pode-se perceber que a maior revolução nas escolas de ensino básico foi a troca do giz e quadro negro (que é verde) pelo pincel e lousa branca. Mudança que vem ocorrendo de modo paulatino, não sendo ainda a realidade em muitas escolas. O uso de projetores eletrônicos de imagens tem conquistado espaço, porém ainda de modo muito acanhado e, por vezes, parece apenas ter substituído a escrita na lousa em tempo real pelo texto que foi previamente digitado.

Diante desse quadro, foi realizada uma atividade de campo no ensino de matemática com a utilização de TIC como instrumento durante seu desenvolvimento. Tendo como objetivo o de verificar se a atividade de campo pode auxiliar no ensino de razões trigonométricas no triângulo retângulo ao se fazer medidas de alturas de difícil acesso. Para atingir tal objetivo, essa investigação ocorreu com uma turma do $2^{\circ}$ ano do ensino médio-técnico do Instituto Federal de Mato Grosso, Campus Confresa.

Os parâmetros das atividades foram elaborados juntamente com os estudantes, que se dividiram em 3 grupos, realizando as atividades de modo extraclasse e tendo orientações por meio das TIC. Esse estudo mostrou que as atividades de campo podem favorecer o ensino de matemática que habitualmente é realizado dentro da sala de aula, pois os estudantes sentiram-se integrantes do processo e motivados por terem transpassado o ambiente da própria sala de aula. Esta situação, segundo Jacobucci (2008, p. 57), pode ser classificado como a utilização de um espaço não-formal, 
que são "[...] ambientes naturais ou urbanos que não dispõem de estruturação institucional, mas onde é possível adotar práticas educativas".

\section{ATIVIDADES DE CAMPO COMO POSSIBILIDADE METODOLÓGICA NO ENSINO DE MATEMÁTICA}

A utilização diversificada dos métodos didáticos na prática pedagógica de ensino pode propiciar atendimento às distintas necessidades, interesses e motivações dos estudantes e contribuir para envolvê-los no processo de ensino (VIVEIRO; DINIZ, 2009a).

A escolha de uma ou outra estratégia está relacionada diretamente ao conteúdo que se pretende ensinar, aos objetivos que se pretende atingir, ao público, ao tempo e aos recursos disponíveis, dentre alguns demais aspectos. Entre as variadas modalidades didáticas que o professor tem à sua disposição para o ensino de ciências, segundo Krasilchik (2004), uma atividade de campo bem planejada e bem elaborada, constitui-se em uma possibilidade alternativa de atuação metodológica que admite laborar com o estudante diante de suas múltiplas possibilidades de aprendizagem.

Ainda, segundo Pereira e Putzke (1996), o sucesso na prática das atividades téoricas ou experimentais não depende excepcionalmente de materiais e equipamentos sofisticados em ambientes de estudos. Não obstante, ainda de acordo com os autores, tal sucesso depende do prévio planejamento com objetivos claros bem definidos e uma metodologia de ensino que viabilize a redescoberta do conhecimento, que coloquem o estudante como o centro da ação educativa e estimule a criatividade.

Apesar de parecer que indicar a atividade de campo como uma estratégia de ensino seja algo novo no que tange ao ensino de matemática, é importante mencionar que sua prática no ensino de ciências é explorada há um tempo relevante. Talvez tal aparência de atividade nova no ensino de matemática se dê pelo fato de ainda não ter suas potencialidades didáticas devidamente exploradas.

Todavia, há na literatura nacional alguns trabalhos desenvolvidos neste contexto, podendo citar o trabalho de Menegazzo et al (2014, p. 22) que 
objetivou "discutir a importância e as possibilidades dos espaços alternativos à sala de aula como potencializadores de aprendizagem significativa na abordagem de conteúdos de maneira interdisciplinar".

O trabalho de campo possibilita a sociabilidade dos estudantes, pois ali podem ser percebidos valores importantes como a partilha, a solidariedade e o fortalecimento dos laços sociais. Nesse tipo de aula prática, em que ocorre a observação de campo, o método empírico pode levar à obtenção dos dados requeridos, constituindo-se em relevante caminho para a compreensão de uma dada realidade. Se for bem trabalhado pelo professor, permite ao aluno sair do contexto de sala de aula e interagir com outros elementos que ajudarão a dar significado, facilitando o aprendizado, oportunizando, às vezes, que apenas uma aula de campo tenha a validade de muitas aulas teóricas.

No âmbito nacional, segundo Balzan (1987, apud VIVEIRO e DINIZ, 2009a) o estudo do meio teve seu início datado nos anos finais da década de 1950, com a instauração das classes experimentais, em escolas públicas e privadas específicas, com embasamento em uma portaria do Ministério da Educação e Cultura, e seu ápice veio com a criação dos Ginásios Vocacionais e Colégios de Aplicação, no início da década de 1960.

Segundo Viveiro e Diniz (2009a, p. 27),

\begin{abstract}
Dentre as diversas estratégias a que o professor da área das Ciências pode recorrer (aulas expositivas, discussões, demonstrações, aulas práticas de laboratório, entre outras), a atividade de campo pode constituir uma excelente alternativa metodológica que permite explorar múltiplas possibilidades de aprendizagem dos alunos, desde que bem planejada e elaborada.
\end{abstract}

Nas palavras de Fernandes (2007, p. 22), atividade de campo é entendida como "toda aquela que envolve o deslocamento dos alunos para um ambiente alheio aos espaços de estudo contidos na escola". No entanto, percebe-se que essa definição não é suficiente para definir atividade de campo, visto que não contempla as indicações supracitadas de Viveiro e Diniz (2009a). Ainda, segundo Libâneo (2013, p. 189) as atividades devem ter o aspecto de não se restringir a visitas ou excursões, 
mas "a todos os procedimentos que possibilitam o tratamento, a discussão e a compreensão de problemas concretos do cotidiano do aluno (...) vivamente enriquecido com visitas a locais determinados".

Viveiro e Diniz (2009a, p. 30) ainda versam de forma clara sobre isso, pois,

É importante salientar que uma atividade de campo compreende não só a saída propriamente dita, mas as fases de planejamento, execução, exploração dos resultados e avaliação. Limitar essa atividade apenas à visita constitui-se em um desperdício das potencialidades passíveis de serem trabalhadas por meio dessa modalidade didática.

Ou seja, a atividade de campo não se constitui somente da retirada dos estudantes do ambiente habitual de aulas e sua inserção em um novo ambiente. Há fatores a serem elencados como o planejamento, a finalidade e se o ambiente realmente possui potencial de fomentação ao ensino ou à aprendizagem. Podendo também afirmar, segundo Viveiro e Diniz (2009b, p. 2), "que as atividades de campo são estratégias muito utilizadas no estudo do meio, mas as duas expressões não têm o mesmo significado".

Corroborando com o que afirmam Viveiro e Diniz (2009a) a respeito da avaliação de uma aula de campo, Lima e Assis ressaltam que

[...] na avaliação, o professor, juntamente com os alunos, deve fazer um balanço dos aspectos positivos e negativos do Trabalho de Campo. [...] Dada à riqueza de uma atividade como esta, seria um desperdício se não houvesse uma culminância (LIMA; ASSIS, 2004, p. 112).

Carbonell (2002) ressalta as potencialidades das atividades de campo e afirma que a mente possui a capacidade de aprender e armazenar melhor as informações no momento em que o corpo interatua ativamente na exploração de lugares. Em sentido oposto, as experiências em que o sujeito é heterônomo possuem tendência a ter impacto de curta duração e perdem-se com o tempo. Assim, o pesquisador afirma que

[...] são necessários espaços físicos, simbólicos, mentais e afetivos diversificados e estimulantes (...), aulas fora da classe, em outros espaços da escola, do campo e da cidade. Porque o bosque, o museu, o rio, o lago (...), bem aproveitados, convertem-se em excelentes cenários de aprendizagem (CARBONELL, 2002, p. 88).

Revista Exitus, Santarém/PA, Vol. 8, № 2, p. 219 - 243, MAl/AGO 2018. 
Segundo Compiane (2007), em uma concepção formativa, as atividades de campo acentuam a semelhança entre o fazer e o aprender ciência, não existindo (ou dirimindo a importância de) quem ensina por meio de "transmição de verdades". Entretanto, surgindo os que aprendem realizando uma ciência escolar. Ainda segundo o autor, o domínio do discurso por parte do professor em sala de aula tradicionalmente pensada é visivelmente rompido, já que não existem a mesa do professor e a lousa. Durante a atividade de campo, tudo pode prender a atenção do estudante, ser fonte de informações, de problemas e dados a serem trabalhados.

No entanto, Viveiro (2006, p. 36) adverte que embora a crença de que as atividades de campo possibilitam 0 fornecimento de importantes contribuições ao ensino escolar, o modo como são desenvolvidas pode restringir uma exploração mais eficiente das potencialidades que as caracterizam. Ainda segundo a autora, "em grande parte dos trabalhos de campo formais o integrante se vê parte de processos semelhantes aos que se estabelecem no interior das salas de aula, havendo quase uma transferência das aulas expositivas para o campo".

Desse modo, no próprio campo foco das atividades e nas posteriores aulas na sala, a questão do domínio do conhecimento somente pelo professor é desfocada. Já que os próprios estudantes irão trabalhar com o material coletado, realizar novas pesquisas visando soluções para o problema envolvido nas atividades e enfatizar a prática escolar por meio da investigação. Em que esta estará permeando todo o processo de realização da atividade, desde sua introdução até as conclusões.

Corroborando com esse pensamento, Frutos et al (1996) afirma que dessa maneira, o estudante tem a possibilidade de aprofundar conhecimentos ao poder confrontar teoria e prática. Ainda segundo os autores, uma atividade de campo permite que o estudante se sinta e seja protagonista em sua aprendizagem, sendo assim um integrante ativo e não um mero receptor de conhecimento. 
Diante de toda explanação sobre atividades de campo realizada, surge a questão que é indicada no título dessa seção: A atividade de campo pode ser utilizada para prover ambientes propícios ao ensino e à aprendizagem de matemática? Viveiro e Diniz (2009a) indicam que, para além de conteúdos específicos, uma atividade de campo pode permitir também criar relações, ou estreitar as já existentes, de estima entre o professor e estudantes, de modo a favorecer um companheirismo que é consequência da experiência em comum e da convivência agradável entre os sujeitos envolvidos. Assim sendo, acredita-se que as atividades de campo podem vir a ser uma metodologia viável para aprimorar a relação tríade entre estudante, professor e conhecimento, visando maior aperfeiçoamento no ensino de matemática.

\section{UTILIZAÇÃO DE TIC EM ATIVIDADES DE CAMPO}

O termo TIC, segundo Miranda (2007), refere-se à conjugação da tecnologia computacional com a tecnologia das telecomunicações e tem na Internet a sua mais forte forma de expressão. Assim, com o constante avanço das inovações tecnológicas que subsidia o surgimento de novas ferramentas computacionais digitais, os aparelhos eletrônicos estão cada vez mais presentes no espaço escolar. Mesmo que haja algumas barreiras para a aceitação plena de tecnologias nesse ambiente, elas têm adentrado na escola devido ao constante uso dos estudantes e professores, mesmo que esse adentramento não tenha cunho educacional. Segundo Strasburg, Sperotto e Meneghetti (2015), diante dessa realidade, cabe ao professor buscar novos métodos e práticas pedagógicas visando um ensino mais atrativo, útil e que desperte o interesse do estudante e facilite o processo de ensino utilizando ferramentas que atualmente são tão familiares a eles.

De acordo com Souza (2014), dentre as dificuldades encontradas pelos professores de matemática, destaca-se o desafio de propor atividades que sejam interessantes para os estudantes e, concomitantemente, não se desvirtuem das competências fundamentais específicas de cada conteúdo 
ensinado. Diante desta constatação, as TIC são instrumentos de uso constante desses estudantes e, por conseguinte, são aparelhos que naturalmente sabem manusear com propriedade e destreza (LOPES; SANTOS, 2016).

Ampliando um pouco essa perspectiva, Rojas, Ritto e Barbosa (2008, p. 16) indicam que

As tecnologias não estão deixando obsoletos nossos professores e as escolas, porém, estão redefinindo os seus papéis. Certamente, uma proposta que esteve, e está em muitas de suas práticas, extremamente centrada no professor, na transmissão de conteúdos, poderá, num novo ambiente, se desenvolver centrada nos processos de aprendizagem, no desenvolvimento de competências e habilidades (cognitivas, afetivas, interpessoais etc.) do estudante, considerado como sujeito ativo no processo de aprendizagem.

Habitualmente as pesquisas e os relatos de experiências são realizados de modo que visam trazer as TIC para dentro da sala de aula. A pesquisadora Lopes (2013) fez um levantamento de pesquisas que analisam as potencialidades das $\mathrm{TIC}$ em sala de aula ressaltando a sua relevância no ensino de Matemática e concluiu que "[...] incluir os recursos da informática como parte das atividades em sala de aula, tem-se a possibilidade de o aluno realizar descobertas, incentivando a compreensão e dando significado ao conhecimento matemático" (LOPES, 2013, p. 633).

Diante desse contexto de pesquisas voltadas para a práxis docente em sala de aula com o uso das TIC, esse trabalho teve o diferencial de levar práticas de estudos que comumente são realizadas em sala de aula para um ambiente que é familiar ao estudante e tendo a utilização de instrumentos que ele mesmo possui.

\section{PROCEDIMENTOS METODOLÓGICOS DE PESQUISA}

Essa investigação foi realizada com o $2^{\circ}$ Ano do Ensino Médio-Técnico em Agropecuária do Instituto Federal de Mato Grosso (IFMT), Campus Confresa, situado na cidade de Confresa, região Araguaia-Xingu do estado de Mato Grosso, durante o primeiro bimestre do ano letivo de 2017 (15 de maio a 26 de junho de 2017). A turma foco dessa pesquisa foi escolhida por 
ser a única turma de ensino médio que o pesquisador atua e também possuir uma quantidade considerada pequena de estudantes, que totalizam 18. Este quantitativo propiciou o bom desenvolvimento das orientações das atividades, pois seria dificultoso se trabalhasse com um quantitativo muito superior a esse.

Inicialmente foram realizados estudos em sala de modo habitual, com explicações no quadro branco por meio de desenhos sobre as razões trigonométricas, realização de exercícios para aprimorar a prática e problemas que visavam contextualizar a trigonometria em algo familiar aos estudantes. Posteriormente a essas atividades, foi proposto a eles que fizessem o cálculo da altura de algum monumento do Campus que seja de difícil medição e informados que existem alguns aplicativos gratuitos para smartphones que auxiliam na medição de ângulos. É importante destacar que a atividade não foi impositiva, tendo a elaboração realizada em aula juntamente com os estudantes. A escolha por essa elaboração conjunta se deu pelo fato de acreditar que desse modo os estudantes se sentiriam integrantes das atividades planejadas e não meramente executores de ordens impostas pelo professor.

Então, nesse planejamento conjunto sobre a execução das atividades, ficou estabelecida a formação de 3 grupos com 6 integrantes para a medição da altura da caixa d'agua (Grupo 1), a guarita da entrada do Campus (Grupo 2) e o para-raios (Grupo 3) em relação ao solo. Também ficou decidido que as atividades seriam realizadas em momentos fora dos horários de aula, devido ao prazo para a realização da atividade e entrega de um breve relatório descrevendo-as foi de 15 dias devido à quantidade de aulas que possuem e ter a possiblidade de orientações durante a realização das atividades.

O aplicativo gratuito escolhido para a realização das atividades foi o DiopThrace, que, segundo os estudantes, tem uma interface intuitiva de fácil manuseio e tem um tamanho relativamente menor que os demais que encontraram. Em que essa escolha foi unânime dentre os 3 grupos. Devido às atividades serem em lugares e momentos distintos, criou-se a possibilidade 
de utilizar aplicativos de comunicação instantânea como instrumento auxiliar na comunicação entre o professor e os estudantes durante a execução de atividades. Ainda teve as orientações presenciais também uma forma de auxílio. No entanto, todas as orientações foram realizadas pelo aplicativo gratuito WhatsApp, que possibilita o envio de áudio, texto e imagens. Este comunicador, por escolha dos executores das atividades, foi o único meio utilizado para a orientação em todo processo de realização das atividades pelos estudantes.

\title{
RESULTADOS E DISCUSSÕES
}

Seguindo as orientações de Viveiro e Diniz (2009a) sobre a utilização diversificada dos métodos didáticos no processo de ensino, percebeu-se que diante de toda execução das atividades, desde a elaboração do plano de trabalho em conjunto até a entrega dos relatórios, houve interesse e motivação por parte dos estudantes por envolvê-los no processo de ensino.

O Grupo 1, responsável pela medição da altura da caixa d'água, elaborou o seguinte breve relatório4:

\begin{abstract}
Nossa atividade foi feita no dia 1 de junho de 2017 na quinta feira, logo após as aulas, nossas maiores dificuldades nem foi tanto na elaboração dos cálculos, mas sim a de encontrar um medidor (trena), para que possamos medir a distância da sombra, nós fomos ao local (caixa d'água), algumas vezes para tiramos as nossas dúvidas. Em nossa primeira vez tivemos a oportunidade de encontramos a sombra. Então resolvemos, fazer com o uso da sombra tirando como ponto de referência o final dela, com apenas 4,20 metros de distância da caixa de água, com um ângulo de $54^{\circ} \mathrm{e}$ a distância encontramos a altura de aproximadamente 6 metros.

Desconfiados dessa altura fizemos o teste novamente no dia sequente e, como nós não podíamos dar mais uma viagem perdida, com sorte nos podemos encontrar uma estaca a 7,9 metros da base da caixa d'água. Desconfiados com essa altura de 6 metros encontrada, tivemos dois bravos rapazes para medir essa caixa de água, podemos alcançar uma altura de 8 metros. Fizemos os cálculos novamente, com a estaca de uma distância de 7,9 metros e um ângulo de $45^{\circ}$ graus pode obter a altura da caixa d'água de 7,9 metros. Assim concluímos nesse trabalho que além de enfrentar vários obstáculos nós conseguirmos obter uma altura aproximada.
\end{abstract}

\footnotetext{
${ }_{4}$ Os breves relatórios serão disponibilizados na integra para que o leitor possa ter contato direto com os mesmos, no intuito de proporcionar um maior envolvimento na leitura e não o deixar pautado somente nas considerações e interpretações do autor. Assim foram todos os três breves relatórios.
} 
Tendo ainda uma captura de tela referenciando o objeto estudado, como pode ser observado na.

FIGURA 1 - Captura da tela do celular no momento da medição angular para calcular a altura da caixa d'água

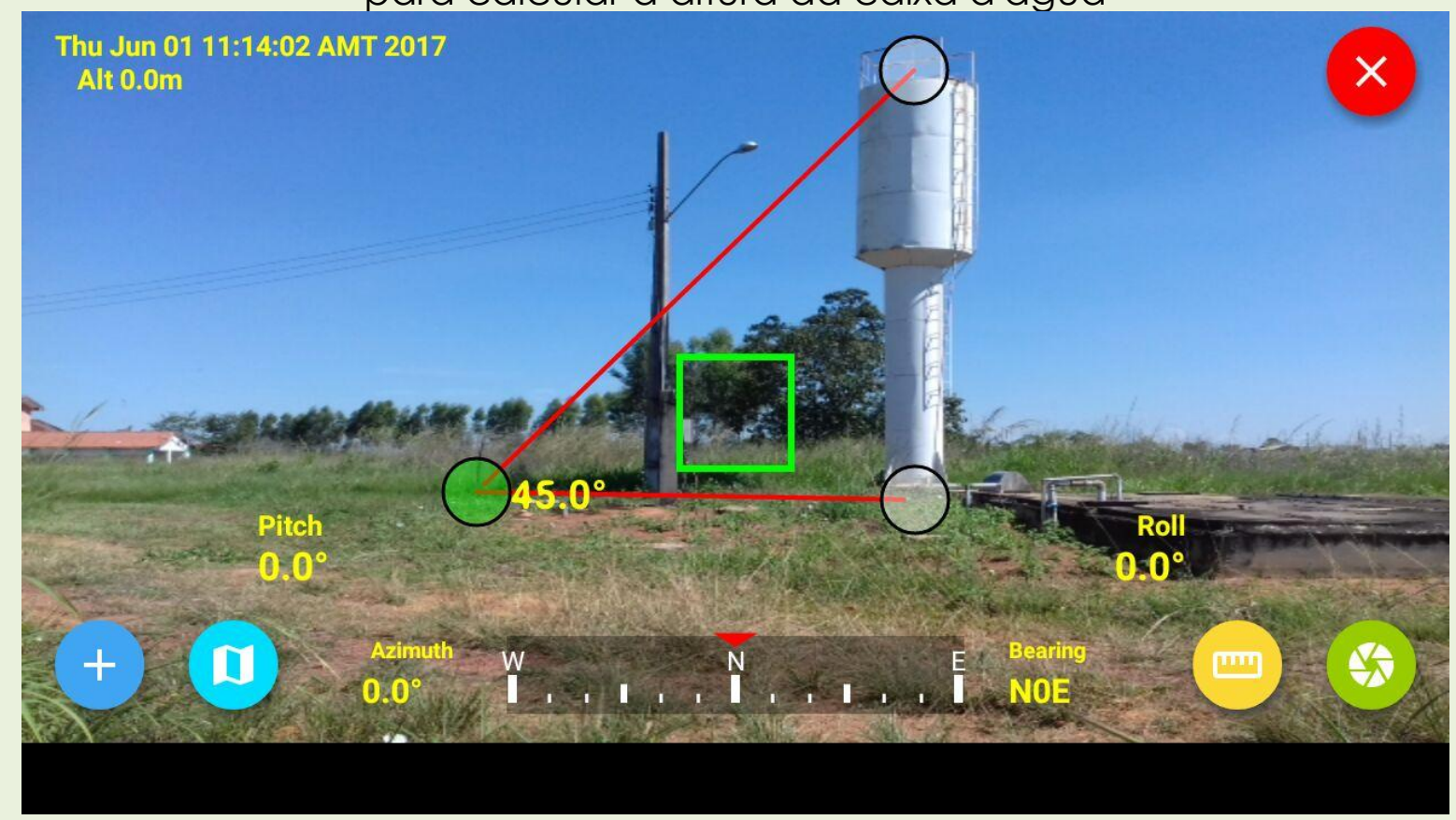

Fonte: Das atividades.

Quanto ao objeto fim do relatório, que é a medição da altura em relação ao solo, o Grupo 1 desenvolveu o seguinte cálculo:

$$
\begin{gathered}
\operatorname{tg} \theta=\frac{\text { CatetoOposto }}{\text { CatetoAdjacente }} \\
\operatorname{tg} 45^{\circ}=\frac{x}{7,9} \\
1=\frac{x}{7,9} \\
x=7,9 \text { metros }
\end{gathered}
$$

Quanto às orientações durante o processo, o Grupo 1 realizou somente 1 contato, que referiu à perceberem alguns entraves na modelação de um triângulo retângulo no esquema a ser estudado. Pois foi relatado por esse grupo que a caixa d'água não era simples para representar em forma de 
um cateto, visto que ela possuía uma dimensão de largura e que a linha imaginária do seu topo até o fim da sombra não seria exatamente uma hipotenusa. Diante disso, o professor orientador questionou que se fizessem uso de uma linha imaginária imaginando o "centro" da caixa d'água, esse entrave ainda iria persistir. $O$ grupo decidiu que não e assim fizeram 0 modelo matemático que pode ser observado na FIGURA 1.

Um momento relevante desse breve relatório foi que os estudantes, pautados equivocadamente na sombra (isso talvez se deva ao comum uso de sombras para medição de alturas em atividades nos livros didáticos), duvidaram da altura de 6 metros que conseguiram. E no dia seguinte voltaram ao local e, antes de realizar a nova medição com a estaca como um ponto de referência, mediram a caixa d'água com a treina que tinham. Após esse novo modelo montado, encontraram a altura de 7,9 metros, que é 0,1 metro menor que a altura medida com a trena, 8 metros.

Concluíram que "nesse trabalho que além de enfrentar vários obstáculos nós conseguirmos obter uma altura aproximada" (Grupo 1). Talvez esse erro de precisão se deva ao fato da medição da estaca até a base da caixa d'água não ter sido uniforme, pois o grupo mediu até a parte da "frente" da base dessa caixa enquanto no modelo matemático se estabeleceu o "centro" dessa base. Possivelmente se o professor tivesse orientado a imaginar uma linha no ponto da base mais próximo da estaca, o resultado poderia ter tido um erro de precisão ainda menor.

O Grupo 2, responsável pela medição da altura da guarita da entrada do Campus, elaborou o seguinte breve relatório:

Primeiramente, usamos o aplicativo DiopThrace para descobrir os ângulos do triângulo que poderia ser formado a partir da estrutura da guarita para então descobrir o cateto adjacente e assim descobrindo o cateto oposto e logo após, utilizando esses dados descobrir a altura aproximada da guarita. Para usar o aplicativo para medir o ângulo da guarita, primeiro tivemos que estabelecer um ponto de referência, que no caso foi a placa que fica a aproximadamente $10 \mathrm{~m}$ da guarita, logo medimos o ângulo do triângulo, que deu $29,7^{\circ}$ mas aproximamos para $30^{\circ}$ para que os resultados fossem mais claros. Logo após obtermos esses dados fizemos os seguintes procedimentos, primeiro descobrimos a Tg de $30^{\circ}$ que é $\frac{\sqrt{\sqrt{2}}}{\mathrm{a}}$. Logo após prepararmos os dados e aplicamos a fórmula da 
seguinte maneira:

$$
\begin{gathered}
\operatorname{tg} 30^{\circ}=\frac{x}{10} \\
\frac{\sqrt{3}}{3}=\frac{x}{10} \\
3 x=10 \sqrt{3} \\
x=\frac{10 \sqrt{3}}{3}
\end{gathered}
$$

Logo após chegarmos a esse resultado, precisamos continuar a operação para descobrir o valor em metros de altura da guarita. Por isso:

$$
x=\frac{10 \sqrt{3}}{3}=\frac{1,79.10}{3}=\frac{17,9}{3}=5,97 \text { metros }
$$

Para melhor compreensão, primeiro tiramos $\sqrt{3}=1,79$, logo após multiplicamos por $10,1,79.10=17,9$ e para obter $\circ$ resultado final dividimos pelo $3,17,9 \div 3=5,97 \mathrm{~m}$ de altura, podendo aproximar para $6 \mathrm{~m}$ de altura.

Para saber se o nosso resultado estava correto, pesquisamos em fontes confiáveis que comprovaram o nosso resultado

O Grupo 2 também acrescentou uma captura de tela referenciando o objeto estudado, como pode ser observado na FIGURA 2.

FIGURA 2 - Captura da tela do celular no momento da medição angular para calcular a altura da guarita

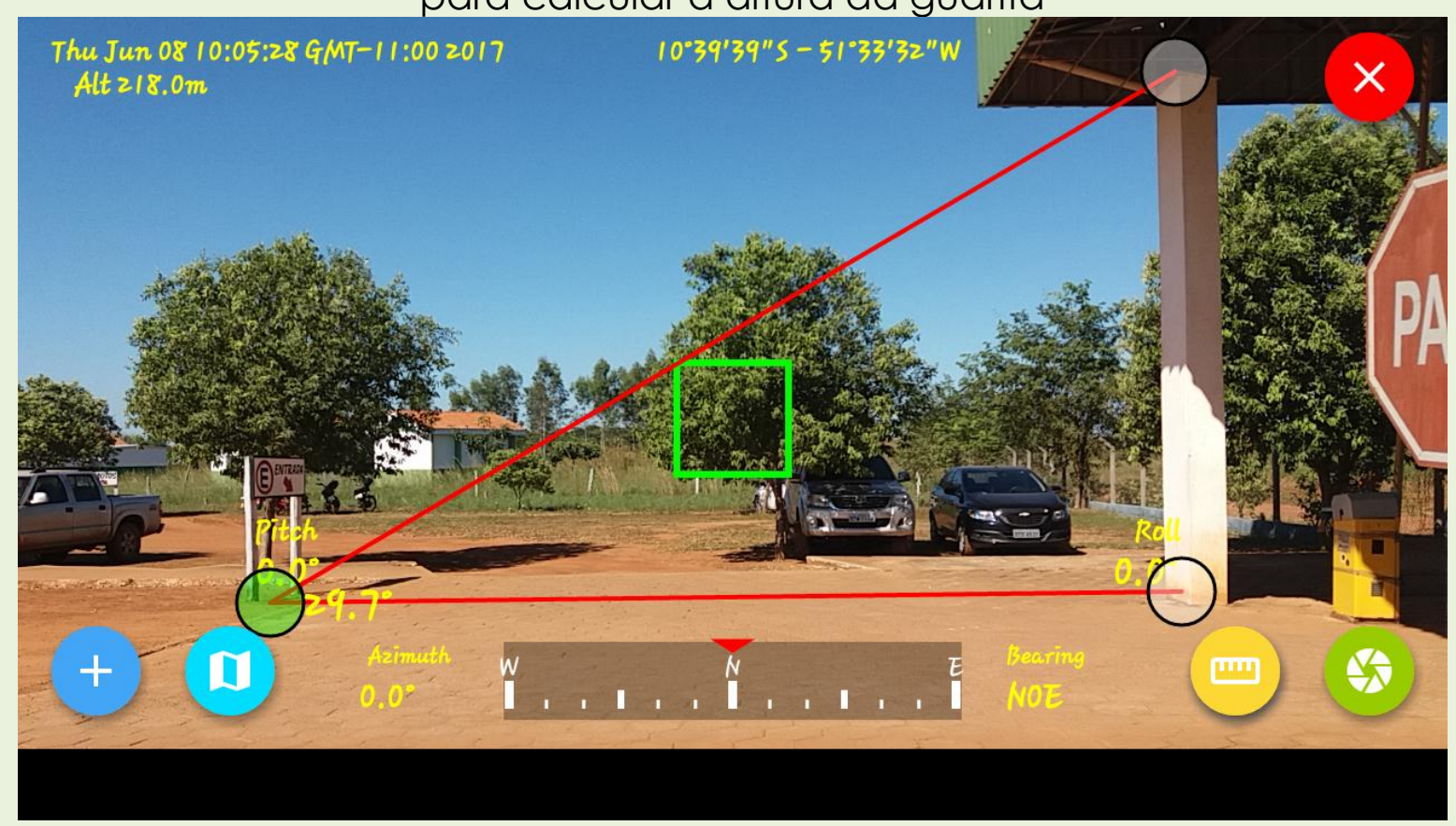

Fonte: Das atividades.

O Grupo 2 foi o que mais procurou auxílio na execução das atividades. Dentre essas orientações destaca-se uma que fez utilização de imagens enviadas pelo WhatsApp. Que tornou possível uma orientação bastante 
clara sobre a modelagem do triângulo retângulo na atividade de campo. Assim pode ser destacada a importância das tecnologias digitais durante a pesquisa. O que corrobora com os estudo de Sperotto e Meneghetti (2015) que indicaram que, diante dessa realidade, cabe ao professor buscar novos métodos e práticas pedagógicas para um ensino mais atrativo, útil e que desperte $o$ interesse do estudante $e$, desse modo, auxilie o processo de ensino utilizando ferramentas que atualmente são tão familiares a eles.

A indagação desse grupo referente a essa orientação em específico, deu-se pelo fato dos estudantes analisarem o modelo realizado por eles e constatarem que visivelmente o modelo matemático formado não era o de um triângulo retângulo. Diante disso, o professor devolveu outra imagem onde explicita o equívoco realizado pelo grupo ao tentarem colocar a situação estudada em um modelo matemático. As imagens podem ser observadas na FIGURA 3.

FIGURA 3 - Imagem à esquerda é a imagem enviada pelos estudantes e à direita é a devolutiva dada pelo professor orientador das atividades
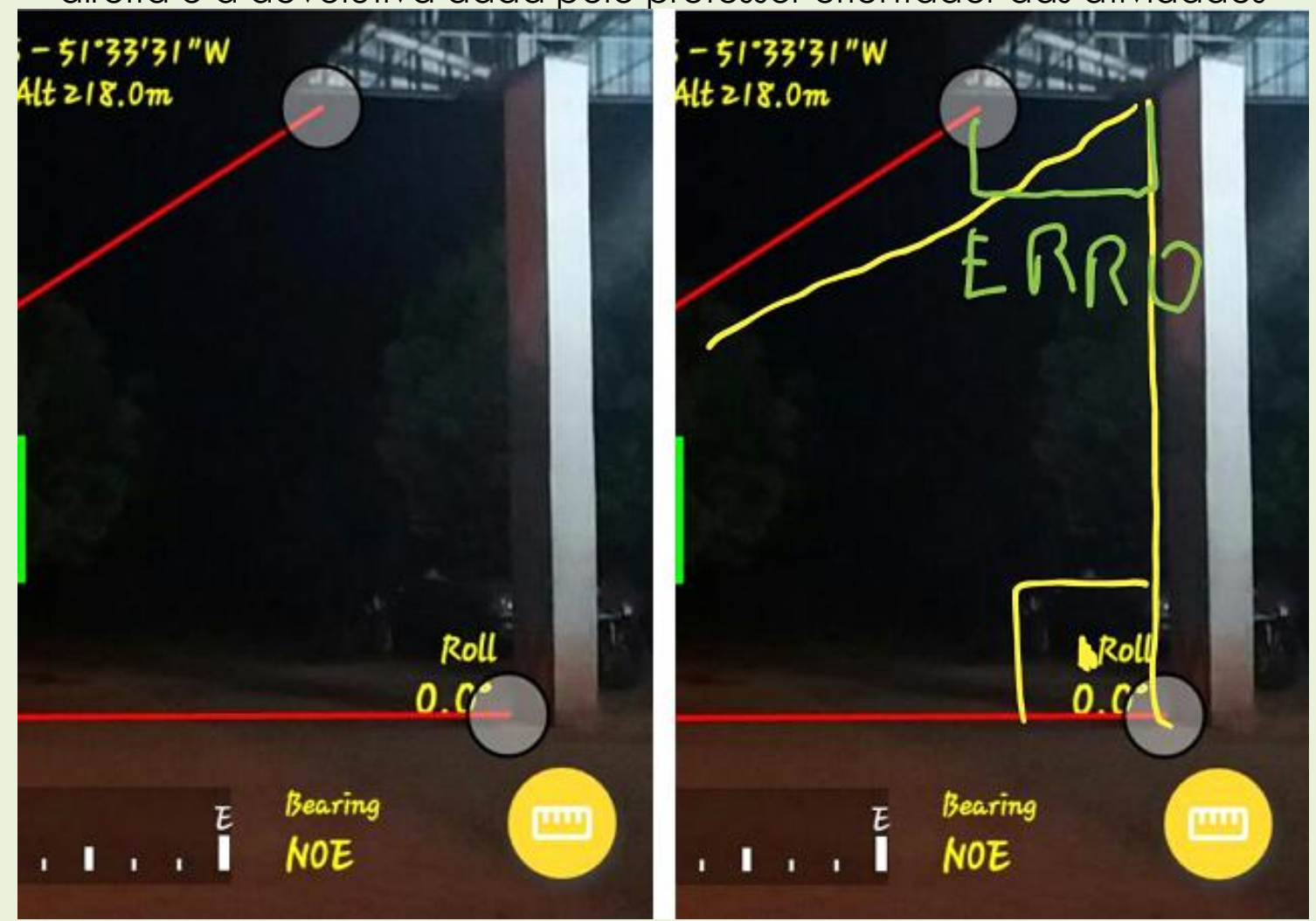

Fonte: Das atividades. 
Quanto ao relato dos estudantes, percebe-se que eles não mencionaram sobre a sombra, que nessa atividade do campo não auxiliaria as atividades devido à parte superior não estar no mesmo sentido ortogonal da coluna de concreto em relação ao solo, entrave muito semelhante ao que o Grupo 1 se viu diante. Um motivo provável para a não utilização da sombra pode ser o fato de incialmente terem realizado as atividades no período noturno (percebível o momento noturno na FIGURA 3). Assim o Grupo 2 teve que traçar uma estratégia que não utilizasse a sombra como referência, tendo então observado uma placa de trânsito estabelecida a aproximadamente 10 metros da base da coluna da guarita.

Também ficou constatado que o Grupo 2 utilizou aproximações para realizar os cálculos, sendo tal ocorrido evidenciado ao colocar que iriam descobrir a altura aproximada da guarita. Isso também é constatado ao afirmarem que a distância entre a base da coluna da guarita e a placa é de aproximadamente 10 metros e no ângulo medido que foi de $29,7^{\circ}$ para $30^{\circ}$. Este último talvez por terem dificuldade em utilizar algum instrumento ou tecnologia que the dariam o ângulo inicialmente medido.

No fim do breve relatório, os estudantes do Grupo 2 afirmam que pesquisaram em fontes confiáveis que comprovaram seu resultado, mas não deixam claro que fontes podem ser essas.

O Grupo 3, responsável pela medição da altura do para-raios elaborou o seguinte breve relatório:

\footnotetext{
Para o desenvolvimento da mesma se fez necessário o uso do aplicativo 'DiopThrace', e também de uma trena; o para-raios utilizado foi o que se localiza ao lado da Administração do Campus Confresa; na qual a atividade proposta foi bastante interessante, uma vez que se tornou possível a melhor fixação do conteúdo, uma vez que se fez possível a assimilação do teórico na prática de uma forma interessante.
}

Não diferente dos outros dois grupos supracitados, o Grupo 3 também colocou uma captura de tela no breve relatório com o intuito de referenciar o objeto estudado. Com um diferencial em relação aos demais, pois o grupo optou por utilizar o ângulo formado pelo cateto oposto e a hipotenusa ao 
invés do ângulo formado pelo cateto adjacente e a hipotenusa como os outros dois grupos, como pode ser observado na FIGURA 4. Que devido à altura do monumento a ser medida, a perspectiva posicional da imagem não favoreceu a constatação ou não da ortogonalidade do para-raios em relação ao solo. No entanto ele é preso por cabos de aço ao solo e, observando por fora da tela do smartphone, dá a impressão que esteja em posição ortogonal ao solo, ou muito próximo disso. Ou seja, a imagem não favoreceu tal constatação, mas é verossímil que o para-raios seja ortogonal ao solo.

FIGURA 4 - Captura da tela do celular no momento da medição angular para calcular a altura do para-raios

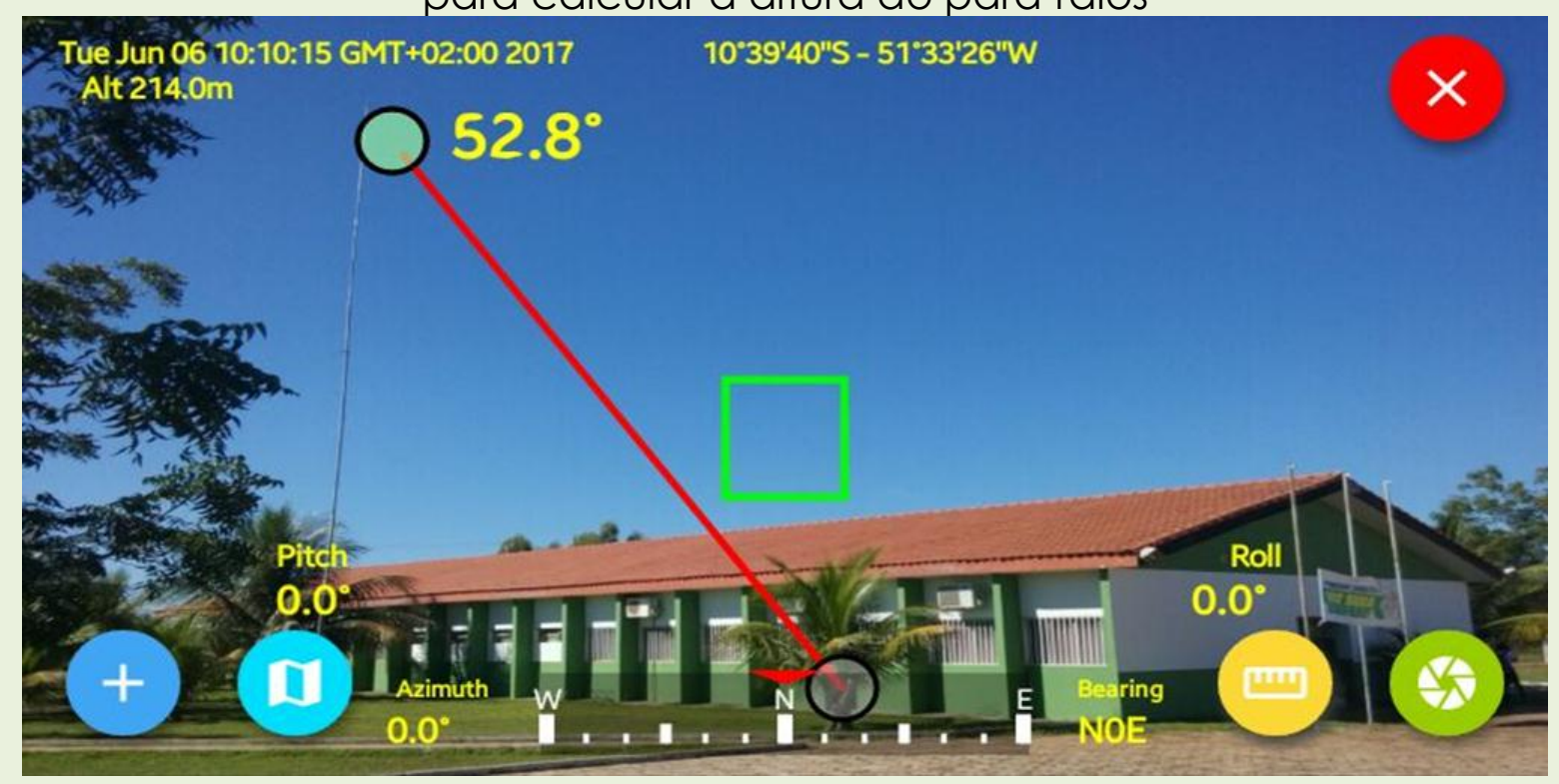

Quanto à medição da altura em relação ao solo, o Grupo 3 apresentou o seguinte procedimento de cálculo: 
FIGURA 5 - Modelo matemático que representa a situação problema da atividade de campo realizada

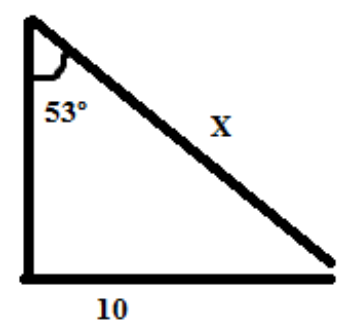

Fonte: Do breve relatório de atividades do Grupo 3.

$$
\begin{gathered}
\operatorname{sen} 53^{\circ}=\frac{10}{x} \\
0,79=\frac{10}{x} \\
0,79 x=10 \\
x=\frac{10}{0,79} \\
x=12,66 \text { metros }
\end{gathered}
$$

Fazendo posteriormente o uso do Teorema de Pitágoras para continuar a estratégia traçada para resolução do problema. Em que realizaram o seguinte cálculo:

$$
\begin{gathered}
a^{2}=b^{2}+c^{2} \\
a^{2}=12,66^{2}+10^{2} \\
a^{2}=160,28+100 \\
a^{2}=260,28 \\
a=\sqrt{260,28} \\
a=16,13 \text { metros }
\end{gathered}
$$

Então, concluíram (equivocadamente) que a altura do para-raios é de 16,13 metros. 
O Grupo 3 não pediu qualquer tipo de auxílio ou orientação durante as atividades por ele realizadas. Entregando o breve relatório no último dia de prazo. No texto do breve relatório não são exploradas as estratégias que os estudantes adotaram para a atividade de campo, só deixando claro que utilizaram uma trena como instrumento para medir a distância entre os dois pontos de referência no solo. No entanto, foi o único grupo a colocar de modo matemático formal a situação estabelecida, por meio da imagem representada na FIGURA 5.

Quanto à estratégia para o desenvolvimento do cálculo, esse grupo também adotou uma postura diferente em relação aos demais. Alterando a função do DiopThrace para medição do ângulo que não esteja na base do triângulo retângulo modelado. E ainda utilizando a razão seno como início e - Teorema de Pitágoras como fim da estratégia traçada para calcular a altura do para-raios. A estratégia traçada está correta e requer um uso de maiores informações e elaborações que as dos demais grupos que optaram pela escolha direta da razão tangente.

O equívoco que resultou na altura de 16,13 metros não foi causado pela estratégia traçada, mas na realização do cálculo do Teorema de Pitágoras em que os estudantes não definiram corretamente os catetos e a hipotenusa. Ou seja, foi um equívoco ao estabelecer as relações das medidas dos lados do triângulo retângulo que causou a medição incorreta da altura do para-raios, e não alguma incorreção na estratégia elaborada.

Por fim, os estudantes do Grupo 3 afirmam que a atividade "proposta foi bastante interessante, uma vez que se tornou possível a melhor fixação do conteúdo, uma vez que se fez possível a assimilação do teórico na prática de uma forma interessante" (Grupo 3).

Diante dos breves relatórios dos grupos, pôde-se constatar o interesse dos estudantes em realizar cada atividade de campo que the foi atribuída. Parte disso é consequência de ter sido explorada a potencialidade da atividade de campo com o incremento da utilização das TIC. Que, corroborando com Carbonell (2002), propiciou uma melhor aprendizagem 
devido à mente ter sua capacidade cognitiva mais apurada no momento em que o corpo interatua ativamente na exploração de lugares.

Com a utilização auxiliar das $\mathrm{TIC}$, que os estudantes naturalmente sabem manusear com propriedade e destreza por serem instrumentos familiares de utilização constante (LOPES; SANTOS, 2016), verificou-se também que é viável a utilização dessas TIC na prática de atividades de campo. Ampliando, dessa forma, a conclusão que chegou Lopes (2013), em que ao introduzir os recursos da informática como instrumentos pedagógicos para a realização das atividades em sala de aula, tem-se a perspectiva de o estudante realizar descobertas, incentivando a compreensão e dando significado ao conhecimento matemático.

\section{CONSIDERAÇÕES FINAIS}

Levando em consideração a experiência de anos anteriores na qual era evidente as dificuldades apresentadas pelos estudantes no estudo e, principalmente, na aplicação da trigonometria, foi proposto esse trabalho com a finalidade de estabelecer uma ponte entre as atividades de campo e o ensino de matemática, utilizando as TIC como meio de integração entre esses dois campos.

Durante o processo de realização das atividades planejadas em conjunto, houve a possibilidade de observar o desempenho dos estudantes, levando em consideração o modo como eles planejaram, escolheram instrumentos de auxílio e executaram as atividades, a interação que existiu entre os membros de cada grupo, as TIC, o professor e o ambiente no qual estão dispostos.

Ainda tendo fundamento baseado em experiências vivenciadas em anos anteriores, quando a aplicação de razões trigonométricas era realizada somente em exercícios do livro e dentro da sala de aula, percebeu-se que houve um aprimoramento nesse processo educacional. Visto que ocorreu efetiva participação na realização das atividades planejadas e a aplicação em situações no ambiente que Ihe é familiar. Mesmo um grupo tendo 
cometido um pequeno equívoco na aplicação do Teorema de Pitágoras, a estratégia elaborada foi correta.

Verificou-se, ainda, que a interatividade proporcionada pela atividade de campo subsidiada pela TIC contribuiu para que os estudantes articulassem melhor o pensamento matemático na busca da solução para a situação estabelecida, sendo assim um elo articulador entre a teoria matemática e a prática em sua realidade.

Diante disso, considera-se que o objetivo almejado na elaboração dessa pesquisa foi alcançado, pois as atividades realizadas possibilitaram aos estudantes realizar uma maior interação entre a teoria e a prática, conseguindo fazer uso de conceitos aprendidos em sala de aula em situações reais e em ambientes onde vivem e convivem.

Desse modo, é almejado que as atividades realizadas possam contribuir para que professores aprimorem seus conhecimentos, suas práticas e compreendam que $\mathrm{o}$ ato de ensinar e $\mathrm{o}$ ato de aprender dos estudantes imergidos nessa sociedade digital exigem a abordagem com novas metodologias de ensino. Assim, adicionando novos significados aos conteúdos estudados e dando possibilidade aos estudantes de empregar as informações para suprir suas necessidades, bem como adquirir competências para interagir conscientemente com o mundo em constante mudança onde vivem.

Um mundo sujeito a reelaborações das concepções sobre o processo de ensino e de aprendizagem da Matemática, que conjecture metodologias inovadoras de ensino concomitantemente relacionadas com os demais campos do conhecimento. Transpassando assim o elucidado por Rojas, Ritto e Barbosa (2008), onde as inovações na sociedade não estão deixando os professores ou as instituições de ensino obsoletos, estão redefinindo os seus papéis como seres e instituições ativas nessa mesma sociedade. 


\section{REFERÊNCIAS}

BALZAN, Newton César. Estudo do meio. In: CASTRO, Amélia Domingues de (Org.). Didática para a escola de primeiro e segundo graus. $9^{a}$ ed. São Paulo: Pioneira, 1987. p. 111-128.

CARBONELL, Jaume. A aventura de inovar: a mudança na escola. Porto Alegre: Artmed, 2002.

COMPIANI, Maurício. O lugar e as escalas e suas dimensões horizontal e vertical nos trabalhos práticos: implicações para o ensino de ciências e educação ambiental. Ciência \& Educação, v. 13, n. 1, p. 29-45, 2007. Disponível em: <http://www.scielo.br/pdf/ciedu/v13n1/v13nla03>. Acesso em: 11 ago' 2017.

FERNANDES, José Artur Barroso. Você vê essa adaptação? A aula de campo em ciências entre o retórico e o empírico. 2007. 326 f. São Paulo: Tese (Doutorado em Educação) - Universidade de São Paulo, São Paulo, 2007. Disponível em: <http://www.teses.usp.br/teses/disponiveis/48/48134/tde14062007-165841/publico/Tese JoseArturBarroso.pdf>. Acesso em: 09 jul. 2017.

FRUTOS, José Antonio de et al. Sendas ecológicas: un recurso didáctico para el conocimiento del entorno. Madrid: Editorial CCS, 1996.

JACOBUCCl, Daniela Franco Carvalho. Contribuições dos espaços nãoformais de educação para a formação da cultura científica. Em extensão, v. 7. n. 1, p. 55-66, 2008. Disponível em: <http://www.seer.ufu.br/index.php/revextensao/article/view/20390>. Acesso em: 12 mar 2017.

KAMII, Constance. A criança e o número: Implicações educacionais da teoria de Piaget para a atuação com escolares de 4 a 6 anos. Tradução de Regina A. de Assis. 39ª ed. Campinas: Papirus, 2012.

KENSKI, Vani Moreira. Tecnologias e ensino presencia e a distância. Campinas: Papirus, 2003. (Série Prática Pedagógica).

KRASILCHIK, Myrian. $4^{a}$ ed. São Paulo: EDUSP, 2004.

LIBÂNEO, José Carlos. Didática. $2^{a}$ ed. São Paulo: Cortez, 2013.

LIMA, Vanuzia Brito; ASSIS, Lenilton Francisco de. Mapeando alguns roteiros de trabalho de campo em Sobral (CE): uma contribuição ao ensino de Geografia. Revista Casa da Geografia, v. 6, n. 1, p. 109-122, 2004. Disponível em: <http://www.uvanet.br/rcgs/index.php/RCGS/article/view/125>. Acesso em: 12 jun 2017.

LOPES, Maria Maroni. Sequência didática para o ensino de trigonometria usando o software geoGebra. Bolema, v. 27, n. 46, p. 631-644, 2013. Disponível em: <http://www.scielo.br/scielo.php?script=sci_arttext\&pid=S0103636X2013000300019>. Acesso em: 12 jul. 2017. 
LOPES, Thiago Beirigo; COSTA, Ademir Brandão da; OLIVEIRA, Ritianne de Fátima Silva de. Estudo de função afim utilizando o software Geogebra como ferramenta interativa. Revista Tecnologias na Educação, v. 8, p. 1-16, 2016. Disponível em: <http://tecedu.pro.br/wpcontent/uploads/2016/09/REL4-ano8-vol17-dez2016-.pdf>. Acesso em: 12 jan 2017.

LOPES, Thiago Beirigo; SANTOS, Leniedson Guedes dos. O uso do Geogebra como ferramenta auxiliar para estudo da reta tangente a um gráfico. RENOTE: Revista Novas Tecnologias na Educação, v. 14, n. 2, p. 1-10, 2016. Disponível em: <http://seer.ufrgs.br/index.php/renote/article/view/70637>. Acesso em: 10 jun. 2017.

MENEGAZZO, Nídia et al. O Horto Florestal Tote Garcia como instrumento pedagógico para $O$ ensino de ciências e matemática: revelando possibilidades e limites. Areté - Revista Amazônica de Ensino de Ciências, v. 7 , n. 13, p. 22-37, 2014. Disponível em: <http://periodicos.vea.edu.br/index.php/arete/article/view/100/99>. Acesso em: 12 jun 2017.

MIRANDA, Guilhermina Lobato. Limites e possibilidades das TIC na educação. Sísifo - Revista de ciências da educação, v. 3, 2007. Disponível em: <https://s3.amazonaws.com/academia.edu.documents/30915238/dcart.pdf ?AWSAccessKeyld=AKIAIWOWYYGZ2Y53UL3A\&Expires $=1503612029$ \&Signature

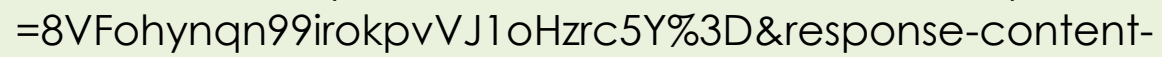

disposition=inline\%3B\%20filename\%3DLimites_e_possibilidades_das_TIC_na_ed UC>. Acesso em: 12 ago 2017.

PEREIRA, Antonio Batista; PUTZKE, Jair. Ensino de Botânica e Ecologia. Porto Alegre: Sagra luzzatto, 1996.

ROJAS, Alexandre; RITTO, Antonio Carlos de Azevedo; BARBOSA, Augusto Cesar Castro. O software livre para o ensino da matemática em instituições de ensino superior: uma tecnologia social. Cadernos do IME - Série Informática, Rio de Janeiro, v. 25, p. 15-26, 2008. Disponível em: <http://www.e-

publicacoes.verj.br/index.php/cadinf/article/view/6510/4631>. Acesso em: 21 jun. 2017.

SOUSA, Reilson Matos de. O uso do geogebra no ensino de função quadrática. 2014. 76 f. Santarém: Dissertação (Mestrado profissional em Matematica) - Universidade Federal do Oeste do Pará, 2014. Disponível em: $<$ http://bit.profmat-

sbm.org.br/xmlui/bitstream/handle/123456789/1 128/2011_00908_REILSON_MA TOS_DE_SOUSA.pdf? sequence=1>. Acesso em: 15 jun. 2017.

STRASBURG, Ezequiel Bobsin; SPEROTTO, Fabíola Aiub; MENEGHETTI, Cinthya Maria Schneider. Atividades de trigonometria para $O$ ensino fundamental com o uso do software GeoGebra. Ciência e Natura, v. 37, p. 617-635, 2015. Disponível em: 
<https://periodicos.ufsm.br/cienciaenatura/article/view/16491/pdf>. Acesso em: 13 jun. 2017.

VIVEIRO, Alessandra Aparecida. Atividades de campo no ensino das ciências: investigando concepções e práticas de um grupo de professores. 2006. 172 f. Bauru: Dissertação (Mestrado em Educação para a Ciência) Universidade Estadual Paulista, 2006. Disponível em: <https://repositorio.unesp.br/bitstream/handle/11449/90877/viveiro_aa_me_b auru.pdf? sequence=1 \&isAllowed=y>. Acesso em: 10 ago 2017.

VIVEIRO, Alessandra Aparecida; DINIZ, Renato Eugênio da Silva. As atividades de campo no ensino de ciências: reflexões a partir das perspectivas de um grupo de professores. In: NARDI, Roberto (Org.). Ensino de ciências e matemática, I: temas sobre a formação de professores [online]. São Paulo: Editora UNESP e Cultura Acadêmica, 2009a. Cap. 2, p. 27-42. Disponível em: <http://static.scielo.org/scielobooks/g5q2h/pdf/nardi-9788579830044.pdf>.

Acesso em: 10 jul. 2017.

VIVEIRO, Alessandra Aparecida; DINIZ, Renato Eugênio da Silva. Atividades de campo no ensino das ciências e na educação ambiental: refletindo sobre as potencialidades desta estratégia na prática escolar. Ciência em tela, v. 2, n. 1, p. 1-12, 2009b. Disponível em: <http://www.cienciaemtela.nutes.ufrj.br/artigos/0109viveiro.pdf>. Acesso em: 09 jul. 2017.

Recebido em: Agosto de 2017

Aprovado em: Março de 2018 